\title{
Poder e limites da razão em Agostinho
}

\section{The Power and the Limits of Reason according to Augustine}

* Mariana Paolozzi Sérvulo da Cunha

Resumo: Neste artigo, focalizamos o poder e os limites da razão em Agostinho, perguntando-nos como a razão, interrogando-se sobre si e sobre o que é o ser humano, revela simultaneamente o conhecimento e a ignorância de si. Embora para Agostinho a razão seja o que possuímos de mais elevado, o que nos diferencia dos animais, e o que, juntamente com a memória e a vontade/amor, nos torna semelhantes a Deus, ela não basta à compreensão da realidade e sequer compreende-se totalmente. Para examinar o alcance e os limites da razão (e, em última análise, a superação de si) no pensamento de Agostinho, partimos do "Quaestio mihi factus sum" ("Tornei-me para mim mesmo uma interrogação", Confessiones X, xxxiii, 50) e seguimos algumas etapas de sua metafísica da experiência interior. Argumentamos que, para Agostinho, o ser humano em seu autoconhecimento é como que incessantemente retirado de si e reapresentado a si mesmo, em uma espécie de esconde-esconde da consciência de si: ele vê e não vê a si mesmo, compreende algo, mas não tudo de si. A potência e as limitações da razão, quando analisadas sob a ótica do conhecimento de si, podem ser compreendidas à luz da relação consciência/inconsciência de si e do papel da memória.

Palavras-chave: Razão. Conhecimento de si. Ignorância de si. Memória.

Abstract: In this article, we focus on the power and on the limits of reason in Augustine's thought: How reason, reflecting in on itself and on who the human being is, reveals concomitantly in both the knowledge and ignorance of itself. For Augustine, reason is the highest faculty we possess, it is what makes us different from other animals. Together with memory and will (love), it renders us similar to God. Nonetheless, he also contends that reason by itself is not enough to grasp reality - it even fails to entirely understand itself. To address the reach and limits of reason (and ultimately, the overcoming of itself) in Augustine, we begin by examining his "Quaestio mihi factus sum" ("I became a question for myself", Confessiones X, xxxiii, 50) and then we revisit some aspects of his inner experience metaphysics. We argue that for him human being in his-/her self-knowledge is as if he/she were

* Doutora em Filosofia. Professora de Filosofia na Universidade Federal de Santa Catarina (UFSC).

\begin{tabular}{|l|l|l|l|l|l|}
\hline Veritas & Porto Alegre & v. 58 & n. 3 & set./dez. 2013 & p. 598-609 \\
\hline
\end{tabular}


ceaselessly removed from, and presented again to him- or herself, in a kind of a hide-and-seek game of "conscience of itself." He/She sees and does not see his-/herself. It understands his-/herself, but only partially. From the perspective of the knowledge of his-/herself, the potency as well as the limits of reason can be grasped in the light of the relationship of one's conscience and unconscience of his-/herself and the role of memory.

Keywords: Reason. Self-knowledge. Ignorance of him-/herself. Memory.

\section{Introdução}

Este artigo busca ressaltar dois aspectos da razão - seu poder e debilidade - por meio do conhecimento e da ignorância de si, isto é, a razão interrogando-se sobre si e sobre quem é o ser humano. Se a razão ${ }^{1}$, para Agostinho, por um lado, é o que possuímos de mais elevado (à diferença dos animais), e é aquilo que nos torna semelhantes a Deus (juntamente com a memória e a vontade/amor) ${ }^{2}$, por outro lado a própria razão não basta à compreensão da realidade: ela sequer compreende-se totalmente - qual afinal a sua origem e o seu fim? -, escapando a si mesma com frequência, lembrando e esquecendo de si.

Em Agostinho, a reflexão sobre o saber de si mesmo pela razão ("Quem sou?"3), no limite de seu alcance, evidencia, curiosamente, o contexto da ignorância de si e a potência/impotência da razão. Ele reconhece (como também facilmente o podemos reconhecer a respeito de nós próprios) que não sabe tudo de si. Assim, a partir do "Quaestio mihi factus sum" - "Tornei-me para mim mesmo uma interrogação"4 - do saber e da ignorância de si, delineia um campo de reflexão mediante o qual é possível, acompanhando a atuação da razão, ver os seus limites, o

1 Em Agostinho, os termos "ratio", "spiritus", "animus", "mens" e "intellegentia", podem se equivaler, dependendo do contexto. Assim, embora possam ter diferentes usos, também admitem sinonímia. Ao longo deste artigo, o vocábulo "razão" será empregado como sinônimo dos termos citados; no entanto, é preciso se precaver quanto aos problemas de homonímia. A razão, aqui, refere-se à parte excelente da alma; os animais possuem "alma" (anima, daí o seu nome), todavia não são dotados de razão. E, nesse sentido, pode-se dizer que, para Agostinho, a razão sempre estará unida à memória e à vontade, como discutido adiante. A respeito da terminologia agostiniana, cf. alguns esclarecimentos de GILSON, E. Introduction a L'Étude de Saint Augustin. Paris: Vrin, 1982, p. 56-57.

2 Sobre a imagem de Deus no ser humano, cf., por exemplo, os capítulos X e XV da obra Da Trindade, de Agostinho.

3 Cf. AUGUSTINUS, Confessiones X, iii, 4.

4 Ibid., X, xxxiii, 50. 
seu alcance e, em última análise, a superação de si. Percorremos a seguir algumas etapas da sua metafísica da experiência interior.

\section{O saber de si mesmo por meio da razão: a consciência de si fragmentada}

Ao refletir sobre o saber de si mesmo, Agostinho depara com uma espécie de distanciamento do ser humano consigo próprio. A razão é consciência de si e das coisas; todavia, não é capaz de apreender-se, nem às coisas, completamente. A conhecida passagem das Confissões ${ }^{5}$, de modo expressivo, sintetiza esse contexto:

[...] nem eu consigo captar o todo que eu sou. Logo, o espírito é estreito para se abarcar a si mesmo: então onde poderá estar o que de si mesmo não abarca? Acaso fora de si mesmo e não dentro de si? Como é que, então, o não abarca?

Se por um lado a razão implica presença a si mesma, consciência de si, na medida em que não se pode abarcar plenamente (nem ao outro), defronta em si própria com uma tensão, espécie de cisão de si: o próprio impedimento de compreender-se de maneira total, a inconsciência de $\mathrm{si}^{6}$. No modo de conhecer a si próprio, o ser humano é como que incessantemente retirado de si e reapresentado a si mesmo, em uma espécie de esconde-esconde da consciência de si: ele vê e não vê a si mesmo; compreende algo, mas não tudo de si.

Não se trata de debater, aqui, as causas dessa cisão - que se manifesta também pela alternância entre consciência e inconsciência ${ }^{7}$-,

5 Ibid., X, viii, 15: “[...] nec ego ipse capio totum, quod sum. Ergo animus ad habendum se ipsum angustus est, ut ubi sit quod sui non capit? Numquid extra ipsum ac non in ipso? Quomodo ergo non capit?". A tradução de algumas passagens das Confissões apresentada aqui é de Arnaldo do Espírito Santo et alii, Lisboa: Imprensa Nacional Casa da Moeda, 2001, revista pela autora em alguns trechos. As outras traduções, ao longo do artigo, foram elaboradas pela autora.

6 Os termos "consciência" e "inconsciência" são empregados neste trabalho em dois sentidos: em sua acepção etimológica primeira, como saber e ignorância de algo (recorrentemente, ao longo do texto, fala-se em consciência ou inconsciência de si: conhecimento ou ignorância de si); ou, dependendo do contexto, os vocábulos "consciência" e "inconsciência" corresponderão a "lembrança" e a "esquecimento". A esse segundo sentido, ou mais propriamente dizendo, à ideia de esquecimento, estaria ligada a noção de inconsciente, cujo significado será apresentado adiante, ao se discorrer sobre a memória e o seu papel.

7 Sem levantar agora a questão do pecado original, essa cisão também pode ser compreendida através da ótica do "minus esse" e "magis esse" no ser humano. Cf. BRUNN, E. Z. Le dilemme de l'être et du néant chez saint Augustin. Amsterdam: Verlag B. R. Grüner, 1984. 
mas identificá-la e configurá-la será suficiente para o intento de mapear a envergadura da razão, que, embora não seja onisciente, dota o ser humano de algum poder. $\mathrm{O}$ intuito de explicitar a potência/impotência da razão exige, previamente, alguns esclarecimentos sobre o sentido da própria razão.

\section{A razão e o seu funcionamento: o abismo entre o conhecimento e o pensamento}

De modo mais preciso, como a razão pode ser compreendida?

Seguiremos, basicamente, o seguinte percurso: (i) será apresentada, inicialmente, uma definição da razão: a ideia de que ela pode ser compreendida como aquilo em nós que conhece; em seguida, (ii) serão postos os seguintes argumentos: se a razão compreende que ela é aquilo em nós que conhece, e que conhece a si mesma, decorre daí que o saber de si é característica intrínseca da razão; (iii) esse saber de si mostra-se como pré-requisito de todo conhecimento (antes de tudo a razão sabe que é aquilo que conhece); (iv) no entanto, esse saber de si se dá sob condições específicas: a razão não se vê inteiramente. A partir daí teremos então os elementos necessários para aprofundar a reflexão sobre a natureza e o limite do autoconhecimento da razão: será abordado o tema da consciência/inconsciência por meio do papel da memória (lembrança de si e esquecimento).

Comecemos pelo significado da razão. Sendo ela aquilo em nós que conhece, tão importante quanto saber isso é a própria razão reconhecer-se como aquilo que conhece: antes de mais nada ela sabe que conhece.

Nesse ponto, emerge uma questão fundamental concernente à autoconsciência da razão: como, por conseguinte, a razão poderia saber que conhece e não se conhecer? O próprio ato de saber que a razão é aquilo em nós que conhece implica conhecer-se (ato de duplo significado). É nela própria que a razão sabe o que é conhecer, e é ela mesma que se conhece como cognoscente. Portanto, a razão conhece a si mesma ${ }^{8}$. Assim, a definição inicial da razão encontra-se expandida: ela não é apenas aquilo em nós que conhece, mas também aquilo que se conhece.

Importa salientar outro aspecto do saber de si: uma vez que o autoconhecimento é característica intrínseca da razão, ele também se apresenta como pré-requisito de todo conhecimento (visto que é a razão que conhece, e ela sabe que conhece). Isso significa que, antes

8 Cf. AUGUSTINUS, De Trinitae X, iii, 5. 
de conhecer as coisas, a razão se reconhece como aquilo que conhece ${ }^{9}$. Não obstante, se para Agostinho a razão compreende a si mesma como aquilo em nós que conhece - o que a leva a ver-se como uma substância espiritual ${ }^{10}$-, e se a sua definição abarca necessariamente o conhecimento de si (saber de si), será inevitável confrontar-se com algo consternador: o que fazer da ignorância de si (o desejo de se conhecer plenamente e a irrevogável frustração desse anseio)? Com efeito, essas afirmações podem parecer contraditórias, uma vez que a própria ideia de razão implica conhecimento de si.

Essa discussão leva-nos a vislumbrar mais claramente a cisão à qual nos referíamos: a razão se conhece, mas não sabe tudo de si, e o que sabe acessa de maneira descontínua (em uma espécie de escondeesconde da consciência de si), isto é, a razão define-se pela capacidade de auto-reflexão ou autoconsciência, mas nem sempre está diante de si pelo pensamento.

Quando a razão pensa sobre si mesma (cogitatio sui), não há um ser apreensível por outro, mas um movimento de conversão da mens que, voltando-se para si, pelo pensamento, compreende que conhece. Entretanto, a razão passa frequentemente de um pensamento a outro

9 Trata-se, aqui, de um conhecimento a priori. As reflexões de E. Gilson a respeito de um inatismo agostiniano caminham nesse sentido. Para compreender o seu sentido específico, cf. GILSON, E. Introduction a L'Étude de Saint Augustin, p. 102.

10 As etapas da refutação de Agostinho ao materialismo podem ser acompanhadas pela análise de BERMON, E. Le cogito dans la pensée de Saint Augustin. Paris: Vrin, 2001, p. 357-360. Como mostrar que os materialistas se enganam ao afirmar que o espírito é corpo e ao negar que o espírito é e vive como inteligência (isto é, uma substância incorpórea)? Bermon examina a seguinte passagem de Da Trindade X, x, 13: "Quando o espírito pensa que ele é, por exemplo, ar, ele pensa que o ar intelige; todavia, que ele próprio intelige, isto ele o sabe: que ele seja ar, ele não o sabe, mas pensa sê-lo. Que ele rejeite o que pensa, e veja o que sabe: que se atenha àquilo que não duvidaram aqueles mesmos que pensaram que o espírito fosse tal ou tal corpo. Pois nem todos são da opinião de que o espírito seja ar; para alguns ele é fogo, para outros o cérebro, para outros um outro corpo, e para outros ainda outra coisa [...] Entretanto, todo espírito sabe que intelige, que é, e que vive". / "Cum ergo, verbi gratia, mens aerem se putat, aerem intelligere putat, se tamen intelligere scit: aerem autem se esse non scit, sed putat. Secernat quod se putat, cernat quod scit: hoc ei remaneat, unde ne illi quidem dubitaverunt, qui aliud atque aliud corpus esse mentem putaverunt. Neque enim omnis mens aerem se esse existimat, sed aliae ignem, aliae cerebrum, aliaeque aliud corpus, et aliud aliae [...]: omnes tamem se intelligere noverunt, et esse et vivere". A passagem de Do livre-arbítrio II, iii, 7 vai no mesmo sentido, ao afirmar a superioridade da vida racional sobre a vida sensitiva e sobre o existir: "Porque, sendo três essas realidades - existir, viver, inteligir - a pedra também existe, e o animal vive; apesar disso não é minha opinião que a pedra viva ou que o animal intelija. [...] pois eu posso afirmar que os cadáveres existem, mas que eles vivem ninguém o diria. Ora, o que não vive muito menos intelige". / "Quia cum tria sint haec, esse, vivere, intellegere; et lapis est, et pecus vivit, nec tamen lapidem puto vivere, aut pecus intellegere. [...] nam esse cadavera possum fateri, vivere autem nullus dixerit. Iamvero quod non vivit, multo minus intellegit". 
(sobre si ou sobre as coisas), e isso significa que o pensamento de si pode se esgueirar e o conhecimento de si recair nas profundezas da memória.

Nesse sentido, lançar mão do autoconhecimento da razão, em Agostinho, mostra-se como excelente recurso para explicitar a sua potência/impotência: a razão oscila entre a consciência e inconsciência (visão e não visão de si). Assim, se ela nos dota de poder de conhecimento sobre si e as coisas, esse poder implica também intermitência de pensamentos - característica do conhecimento discursivo - e incapacidade de apreensão da realidade em ato único.

A presença a si e o conhecimento de si, enquanto vivemos, nunca desaparecem, mas as condições em que se manifestam são claras para a razão: nem sempre pensamos sobre o conhecimento de si; em outras palavras, uma coisa é o conhecimento, e outra coisa o pensar sobre o que conhecemos (ruptura entre o saber e o pensamento) ${ }^{11}$. Assim, faz sentido dizer que a potência/impotência da razão pode ser compreendida pela consciência/inconsciência de si (apreensão e "inapreensão" de si; presença a si e esquecimento de si), que também se expressa pela ruptura entre o saber e o pensamento.

Avançando nessa direção, é possível indagar: visto que a autoconsciência é marca registrada dos seres racionais (o conhecimento de si é pré-requisito do conhecimento racional), uma autoconsciência parcial e discursiva, que se dá pela oscilação dos pensamentos, pode ser tida, de fato, como tal?

Para aprofundar a reflexão sobre a razão e a cisão que envolve conhecimento e ignorância de si, lembrança e esquecimento de si, algumas passagens das obras Confissões, Da Trindade e Da verdadeira religião são significativas.

As Confissões apontam claramente a distância do ser humano com relação a si próprio, na forma de consciência e inconsciência (emerge, ali, expressamente o limite razão):

[...] embora nenhum homem saiba o que é próprio do homem, a não ser o espírito do homem que está nele, todavia há alguma coisa do homem que nem o próprio espírito do homem, que nele está, conhece; mas tu, Senhor, que o fizeste, conheces todas as suas coisas ${ }^{12}$.

Essa insuficiência da razão desembocará na demanda de algo além dela própria (em busca de seu ser e sua razão de ser), explicitando uma

11 Outro exemplo: o geômetra, quando pensa sobre física, não deixa de desconhecer a geometria.

12 Cf. AUGUSTINUS, Confessiones X, v, 7: "[...] quia etsi nemo scit hominum, quae sunt hominis nisi spiritus hominis, qui in ipso est tamen est aliquid hominis, quod nec ipse scit spiritus hominis, qui in ipso est, tu autem, Domine, scis eius omnia, qui fecisti eum". 
exigência de autossuperação. A tentativa, por essa razão cindida, de se reconciliar consigo não será alcançada se ela própria permanecer ensimesmada. A necessária superação de si tornar-se-á expressão de um paradoxo: será preciso buscar a reaproximação consigo através de uma reaproximação com o seu princípio transcendente.

A reflexão agostiniana sobre o cogito ilustra como é que através de uma exigência interna da sua própria atividade a razão transcende a si mesma: "Se me engano, sou" ("Si enim fallor, sum")13. Aqui, a presença da razão a si mesma liga-se à descoberta da verdade frente à dúvida, que, por sua vez, remete à verdade transcendente descoberta no mais íntimo da razão ${ }^{14}$, que não é senão Deus:

[...] se tens certeza da sua dúvida, procura de onde ela vem: não é de modo algum a luz do sol que encontrarás, mas a luz verdadeira que ilumina todo homem que veio ao mundo. [...] Qualquer um que compreende que duvida, compreende uma coisa, e ele está certo dessa coisa que compreende. É de uma coisa verdadeira que ele está certo. Portanto, qualquer um que duvida da existência da verdade, possui nele uma coisa verdadeira da qual ele não duvida: ora, as coisas só são verdadeiras pela verdade. Portanto, não deve duvidar da verdade aquele que pode de algum modo duvidar. Aí onde vemos essas coisas, aí está a luz que não possui nenhuma dimensão de espaço nem tempo, nem imagem alguma dessas dimensões ${ }^{15}$.

O centro de unidade do ser humano estaria além dele próprio, fazendo com que se reconheça, via razão, que o conhecimento de si não se esgota nele próprio (a razão não é autossuficiente nem na explicação de si própria), mas remete à verdade transcendente.

A invocação de abertura do Livro $\mathrm{X}$ das Confissões assinala o necessário deslocamento de foco que é preciso para alcançar a resposta ao "Quem sou?": "Que eu te conheça, ó conhecedor de mim, que eu te conheça, tal como sou conhecido por ti" ${ }^{16}$.

13 Cf. AUGUSTINUS, De civitate Dei XI, xxvi.

${ }^{14}$ Cf. VAZ, H. L. Ontologia e história. São Paulo: Duas Cidades, 1968, p. 93-106 (III - A metafísica da interioridade).

15 Cf. AUGUSTINUS, De vera religione XXXIX, 73: "[...] si certum est te esse dubitantem, quaere unde sit certum: non illic tibi, non omnino solis huius lumen occurret, sed lumen verum quod illuminat omnem hominem venientem in hunc mundum [...] Omnis qui se dubitantem intellegit, verum intellegit, et de hac re quam intellegit certus est: de vero igitur certus est. Omnis ergo qui utrum sit veritas dubitat, in seipso habet verum unde non dubitet; nec ullum verum nisi veritate verum est. Non itaque oportet eum de veritate dubitare, qui potuit undecumque dubitare. Ubi videntur haec, ibi est lumen sine spatio locorum et temporum, et sine ullo spatiorum talium phantasmate".

${ }^{16}$ Cf. AUGUSTINUS, Confessiones X, i, 1: "Cognoscam te, cognitor meus, cognoscam, sicut et cognitus sum". 


\section{A lembrança e o esquecimento de si}

Em $\mathrm{Da}$ Trindade, a cisão de si ganhará outros contornos e a argumentação é aprofundada. A razão não chega a se apreender completamente em um ato único e permanente, divagando na constante alternância dos pensamentos sobre si mesma e as coisas (lembrança e esquecimento de si). Quando busca compreender o que é, o ato do pensamento lhe é necessário para resgatar, atualizar o conhecimento de si presente na memória. Assim, há para Agostinho um duplo conhecimento de si: aquele latente na memória (implícito e pré-reflexivo), e o discursivo (explícito), resgatado pelo pensamento. O que revela, conforme dito, uma espécie de dissociação entre o "conhecimento" (notitia) e o "pensamento" (cogitatio) do espírito sobre si mesmo.

A forma como se dá o distanciamento de si e a presença a si - "abismo da consciência humana"17 - surpreende, justamente porque é possível reconhecer a razão como permanente presença a si. Por mais que a razão queira alijar-se de si, sempre o fará provisoriamente e se deparará consigo própria enquanto viver. Incessantemente, a mente escapa a si mesma, mesmo que presente a si mesma.

Agostinho enfatiza que o conhecimento de si e todo outro conhecimento que não é presentemente pensado estariam na memória ${ }^{18}$, a qual, por sua vez, segundo Étienne Gilson pode ser nomeada de "subconsciente" ou "inconsciente", levando-se em consideração a exigência de ampliar a sua significação:

É evidente que, aqui, como nos textos das Confissões que analisamos, o termo memória significa muito mais do que a sua acepção psicológica moderna: a lembrança do passado. Ele se aplica, em Santo Agostinho, a tudo o que está presente à alma (presença que se verifica por uma ação eficaz) sem ser explicitamente conhecido ou percebido. Os únicos termos psicológicos modernos equivalentes à memória agostiniana são os de inconsciente ou subconsciente, desde que expandidos, como veremos adiante, até incluir, além da presença na alma de seus próprios estados não atualmente percebidos, a presença metafísica de uma realidade distinta dela própria e transcendente, Deus ${ }^{19}$.

17 Ibid., X, ii, 2: "abyssus humanae conscientiae".

18 Cf. AUGUSTINUS, De Trinitate XV, xxi, 40: "memoriae tribuens omne quod scimus etiamsi non inde cogitemus".

19 Cf. GILSON, E. Introduction a L'Étude de Saint Augustin, p. 135, nota 2: "Il est évident qu'ici, comme dans les textes des Confessions que nous analysons, le terme de mémoire signifie beaucoup plus que ce que désigne son acception psychologique moderne: le souvenir du passé. Il s'applique, chez saint Augustin, à tout ce qui est présent à l'âme (présence qui s'atteste par une action efficace) sans être explicitement connu ni perçu. Les seuls termes psychologiques modernes qui soient équivalents à la memoria augustinienne 
Em suma, se é uma característica dos seres racionais (espirituais) que se relacionem inalienavelmente com si mesmos pela autoconsciência (novamente, o conhecimento de si é característica intrínseca da razão), importa notar que, se não faz parte da atual condição do ser humano reconhecer-se pelo pensamento de modo permanente, não obstante isso ocorreria subconscientemente ou inconscientemente. Aqui, irrompe o papel da memória agostiniana20.

Nos vastos recônditos da memória, escondem-se todos os saberes aprendidos e tudo o que pensamos. Aí jaz tudo o que se lhes entregou e depôs21, isto é, tudo o que não tenha sido absorvido e sepultado pelo esquecimento. Na memória, receptáculo cheio de "sinuosidades secretas e inefáveis", diz Agostinho22, estão presentes o céu, a terra e o mar com todos os pormenores percebidos pelos sentidos (excetos os detalhes já esquecidos).

É imprescindível notar que na própria memória também se pode, presentemente, encontrar a si mesmo recordando-se de si (a autoconsciência exige a memória), ou recordando-se, por exemplo, das ações realizadas pessoalmente em um tempo e lugar específicos, e dos sentimentos que as acompanhavam.

Uma vez que a memória mostra-se infinitamente ampla, sondá-la profundamente torna-se tarefa inexaurível. Como explicar que a própria memória retenha, por exemplo, os afetos, sem necessariamente experimentá-los ao serem recordados?

[...] sendo, pois, assim, por que é que quando, estando alegre, recordo a minha tristeza passada, o meu espírito sente a alegria, e a minha memória a tristeza e, estando o meu espírito alegre pelo fato de que nele há alegria, não está triste a minha memória, pelo fato de que nela há tristeza? Acaso a memória não faz parte do espírito? Quem ousaria dizê-lo? ${ }^{23}$.

Agostinho chega a uma definição da memória por meio de metáfora: ela é como o ventre, o estômago da alma:

sont ceux d'inconscient ou subconscient, pourvu qu'on les élargisse eux-mêmes, comme on verra plus loin, jusqu'à inclure, outre la présence à l'âme de ses propres états non actuellement perçus, la présence métaphysique à l'âme d'une réalité distincte d'elle, et transcendante, telle que Dieu".

20 Cf. HÖLSCHER, L. The Reality of the Mind. London-New York: Routledge \& Kegan Paul, 1986, p. 180.

${ }^{21}$ Cf. AUGUSTINUS, Confessiones X, viii, 14.

22 Ibid.

${ }^{23}$ Ibid., X, xiv, 21: "[...] cum ergo ita sit, quid est hoc, quod cum tristitiam meam praeteritam laetus memini, animus habet laetitiam et memoria tristitiam laetusque est animus ex eo, quod inest ei laetitia, memoria vero ex eo, quod inest ei tristitia, tristis non est? Num forte non pertinet ad animum? Quis hoc dixerit?". 
[...], mas a alegria e a tristeza são como uma espécie de alimento doce e amargo; quando são confiadas à memória, como que passadas para o estômago, podem lá ser guardadas, porém não podem ter sabor. [...] Assim como a comida é tirada do estômago, pela ruminação, assim também estas coisas são tiradas da memória, pela recordação ${ }^{24}$.

Atingimos, assim, um importante ponto que nos permitirá apreender melhor a cisão da razão aludida acima: finalmente, tão crucial para a sua compreensão é a questão do esquecimento, reverso da memória.

Quando a razão se recorda da memória, esta se torna presente a si por si mesma. Quando a razão se lembra do esquecimento, estão ao mesmo tempo presentes o esquecimento e a memória: a memória que faz com que nos recordemos, e o esquecimento que lembramos.

Mas, se o esquecimento é a privação de memória, como ele pode ser objeto da memória se, quando está presente, não podemos recordar ${ }^{25}$ ? Como pode o esquecimento, quando presente, gravar a sua imagem na memória, se ele, com a sua presença, apaga tudo o que lá se encontra impresso ${ }^{26}$ ?

[...] Portanto, a presença do esquecimento faz com que o não esqueçamos; mas, quando está presente, esquecemo-nos. Acaso se deve entender a partir disto que o esquecimento, quando nos lembramos dele, não está na memória por si mesmo, mas por meio da sua imagem, uma vez que, se estivesse presente por si mesmo, não faria com que nos lembrássemos, mas sim com que nos esquecêssemos? Finalmente, quem poderá indagar isto? Quem compreenderá como isto é?.

Apesar de essas operações parecerem inexplicáveis e incompreensíveis, constatamos, por outro lado, que é possível lembrar-se do esquecimento (que expurga, ou como diz Agostinho, varre da memória tudo aquilo de que nos lembramos). Constata-se, também, que o esquecimento - ligado à memória de modo inextricável - possui algo de horrendo ${ }^{27}$, que parece remeter ao nada.

24 Ibid.: "[...] laetitia vero atque tristitia quasi cibus dulcis et amarus; cum memoriae commendantur, quasi traiecta in ventrem recondi illic possunt, sapere non possunt. [...] Forte ergo sicut de ventre cibus ruminando, sic ista de memoria recordando proferuntur".

${ }^{25}$ Ibid., X, xvi, 24.

${ }^{26}$ Ibid.: "[...] Adest ergo, ne obliviscamur, quae cum adest, obliviscimur. An ex hoc intellegitur non per se ipsam inesse memoriae, cum eam meminimus, sed per imaginem suam, quia, si per se ipsam praesto esset oblivio, non ut meminissemus, sed ut oblivisceremur, efficeret? Et hoc quis tandem indagabit? Quis comprehendet, quomodo sit?".

27 Ibid., X, xvii, 26: "Grande é o poder da memória, tem um não sei quê de horrendo [...]"./ "Magna vis est memoriae, nescio quid horrendum [...]". 
Expressão de uma cisão interna da razão, o esquecimento total de si, como forma de inconsciência, e também o de Deus, mostram-se aniquiladores. Esquecer-se de si nos aproximaria do nada, pois esquecer-se de si completamente significa o próprio anular da razão - tida como autoconsciência - e do eu. Por sua vez, esquecer-se de Deus, também seria esquecer de si (prolongamento e aprofundamento do esquecimento pessoal). É por isso que nas Confissões a resposta à pergunta "Quem sou?" reporta-se ao conhecimento de si e de Deus, que sempre pede memória e atualização: "Que eu te conheça, ó conhecedor de mim, que eu te conheça, tal como sou conhecido por ti", conforme citado anteriormente.

Em suma, há um afastamento de si mesmo quando não há "memória de si" (memoria sui), e maior ainda quando não há memória de Deus. Notável ainda é perceber esse estado como condição corriqueira do ser humano, ou condição atual, habituado à cisão de si, à alternância entre a consciência e a inconsciência.

\section{Considerações finais}

No conhecimento de si, apreendido pelo pensamento a partir da memória, vemos a possibilidade de encontro do ser humano consigo próprio; é o estado de um ser que, se não é plena e constantemente consciente de si pelo pensamento, o é alternadamente, fragmentadamente. $\mathrm{E}$ isso significa, ao menos, a possibilidade de algum tipo de conhecimento de si (um tomar contato consigo). Todavia, sublinhe-se que a impotência da razão em compreender totalmente a si e às coisas também sinalizará algo importante. Será a partir do reconhecimento dessa debilidade, da alternância entre consciência e inconsciência - mediante a compreensão do funcionamento, da atividade e dos limites da própria razão associada à memória e à vontade -, e por meio de introspecção, que será possível ao ser humano reconhecer-se como símile e imagem da Trindade ${ }^{28}$, voltandose, finalmente, a si mesmo, de novo, com um ganho de compreensão ${ }^{29}$.

Saliente-se, também, que a razão sempre está ligada não apenas à memória, mas também à vontade. Quando a razão busca saber o que

${ }^{28}$ A respeito da concepção da alma como imagem da Trindade, cf. o livro de CUNHA, M. P. S. O movimento da alma. A invenção, por Agostinho, do conceito de vontade. Porto Alegre: EDIPUCRS, 2001.

${ }^{29} \mathrm{Se}$, por um lado, é possível reconhecer-se como imagem de Deus, por outro, a impossibilidade da apreensão total de si e de Deus estará muito clara para Agostinho (a dimensão de mistério do eu e do transcendente); cf. AUGUSTINUS, De Trinitate XV, ii, 2: "[...] pois as coisas incompreensíveis devem ser buscadas de tal modo que não estime nada ter encontrado aquele que pôde encontrar quão incompreensível é aquilo que se buscava"./"Sic enim sunt incomprehensibilia requirenda ne se existimet nihil inuenisse qui quam sit incomprehensibile quod quaerebat potuerit inuenire". 
é, depara-se não apenas com a memória (ao lembrar-se de si), mas também com a vontade de conhecer as coisas, e a si. Desse modo, o conhecimento de si da razão envolve o conhecimento que temos de nossa vida interior como atividade trinitária, isto é, essencialmente as relações entre a memória, a razão e a vontade. Nesse sentido, conhecerse, para Agostinho, implica ver-se como imagem do Deus que é trino, é ver a memória, razão e vontade expressando algo das relações do Pai, Filho e Espírito Santo.

Pode-se dizer que a razão só é propriamente imagem da Trindade quando tem disso consciência. A despeito da cisão de si (da alternância entre consciência e inconsciência), é principalmente a atividade da memória, da razão e da vontade que dotará o ser humano de liberdade e poder de criação, à imagem do criador. Enfim, a razão, em sua primazia, está não apenas associada à memória, mas também à vontade (amor) ${ }^{30}$.

\section{Referências}

AUGUSTINUS. Opera Omnia. Corpus Christianorum, Series Latina. Turnholt: Brepols, 1982-1993.

AGOSTINHO. Confissões. Trad. Arnaldo Monteiro do Espírito Santo et alii. Lisboa: Imprensa Nacional, 2001.

BERMON, E. Le cogito dans la pensée de Saint Augustin. Paris: Vrin, 2001.

BRUNN, E. Z. Le dilemme de l'être et du néant chez saint Augustin. Amsterdam: Verlag B. R. Grüner, 1984.

CUNHA, M. P. S. O movimento da alma. A invenção, por Agostinho, do conceito de vontade. Porto Alegre: Edipucrs, 2001.

GILSON, E. Introduction a l'Étude de Saint Augustin. Paris: Vrin, 1982.

HÖLSCHER, L. The Reality of the Mind. London-New York: Routledge \& Kegan Paul, 1986.

VAZ, H. L. Ontologia e história. São Paulo: Duas Cidades, 1968.

\section{Endereço postal:}

Departamento de Filosofia

Centro de Filosofia e Ciências Humanas - CFH

Universidade Federal de Santa Catarina

88040-900 Florianópolis, SC, Brasil

E-mail: marianapaolozzi1@gmail.com.

Data de recebimento: 09/08/2012

Data de aceite: $10 / 08 / 2013$

30 O tema da intencionalidade do conhecimento está claramente formulado em Agostinho, a tal ponto que, em seu pensamento, é possível definir a razão, em outro de seus aspectos, como razão afetiva: ela é inextricavelmente dependente da vontade (que, em sua forma intensa, é concebida como amor). Só se conhece aquilo que se tem vontade de conhecer. 